\title{
Arrhythmogenic right ventricular cardiomyopathy or athlete's heart? Challenges in assessment of right heart morphology and function
}

\author{
Francesco Antonini-Canterin ${ }^{1}$, Concetta Di Nora ${ }^{2}$ \\ ${ }^{1}$ Cardiac Prevention and Rehabilitation Unit, Highly Specialized Rehabilitation Hospital, Motta Di Livenza; \\ ${ }^{2}$ Cardiothoracic Department, University Hospital Santa Maria della Misericordia, Udine, Italy
}

\begin{abstract}
The incidence of sudden cardiac death (SCD) in young athletes varies among studies, due to the disagreement in the definitions and the lack of information in this field. The estimated annual incidence of SCD in athletes is 1.6 per 100,000 individuals [1]; furthermore, some data confirm that the risk for SCD in athletes is higher than in non-athletes (2.3 vs 0.9 in 100,000 per year) [2]. Syncope that occur during exertion constitutes a red flag for SCD, as also recently underlined [3]. Anymore, the familial history of SCD at young age reinforces the possibility of a serious adverse outcome in this context [4], as far as patients with exercise-associated syncope include groups of patients at higher risk of SCD. The differential diagnosis could become difficult in this scenario: athlete's heart, arrhythmogenic right ventricular cardiomyopathy (ARVC), Brugada syndrome or hypertrophic cardiomyopathy (HCM) has to be all rule out, because all these can present with syncope during exercise without warning [5].

It is known that participation in sports with a high dynamic and static demand causes an increase and structural remodeling of the cardiac mass [6]; so, echocardiography plays a vital role in this context distinguishing between benign athlete's heart and other several pathologic cardiac conditions. Notable, sports training can cause enlargement and increased volume of the right (RV) and left ventricular (LV) chambers, occasionally accompanied by increased LV wall thickness and increased size of the left atrium, with preservation of systolic and diastolic function. Athlete's heart is more likely when these structural abnormalities decrease with short
\end{abstract}

Correspondence: Concetta Di Nora, Cardiothoracic Department, Azienda Sanitaria Universitaria Integrata, Ospedale Santa Maria della Misericordia, P.zza Santa Maria della Misericordia 1, 33100 Udine, Italy.

Tel.+39.040.3994877 - Fax: +39.040.3994491

E-mail: concetta.dinora@gmail.com

Key words: Heart's athlete; arrhythmogenic right ventricular cardiomyopathy; echocardiography.

Received for publication: 12 February 2019.

Accepted for publication: 21 February 2019.

(C) Copyright F. Antonini-Canterin and C. Di Nora, 2019

Licensee PAGEPress, Italy

Monaldi Archives for Chest Disease 2019; 89:1047

doi: 10.4081/monaldi.2019.1047

This article is distributed under the terms of the Creative Commons Attribution Noncommercial License (by-nc 4.0) which permits any noncommercial use, distribution, and reproduction in any medium, provided the original author(s) and source are credited. periods of deconditioning. Furthermore, RV remodeling patterns particularly correlate with exercise subtype, and endurance athletics are mostly characterized by RV elongation and dilation, whereas isometric physical activities induce little change in RV structure [7]. The physio-pathological mechanism could be explained by the fact that the increased cardiac output during aerobic activity greatly expands end-diastolic RV volume, being the RV a non-compacted structure with increased compliance, and with a shape sensitive to loading conditions [8] Hence, it is crucial to evaluate the differential diagnosis because, on one hand, just the detraining could be the therapy; on the other hand, both the medical and device management could be needed.

In this case presented by Brandimarte and colleagues, syncope is the unexpected clinical presentation of a young man during sport activities [9]. The echocardiogram of this patient promptly presents a normal LV in size and dimensions, but a dilated RV with poor function. Recently, several studies have shown that RV chamber dimensions are larger in endurance athletes than those described by "normal ranges" and frequently meet the major criteria for the diagnosis of ARVC [10]. For example, in this prospective observational study performed on 102 endurance athletes, $28 \%$ of the absolute RVOT dimensions fell within the major echocardiographic criteria and $83 \%$ met the minor criteria $(>29$ $\mathrm{mm}$ ) for a diagnosis of ARVC [11]. Furthermore, recent studies, albeit in small cohorts, have demonstrated that some athletes exhibit larger RV dimensions compared to LV chambers [12]. Therefore, the RV/LV ratio could provide valuable information to aid in the further differentiation of physiology from pathology, and a cut-off value of 1.17 for the RV/LV ratio has been proposed as normal in the athlete population [13]. Moreover, cardiac magnetic resonance (CMR) could help in identifying regional RV wall motion abnormalities, volumes and function, and allows assessment of fibrosis and signs of fibro-fatty replacement or infiltration. As in the case presented, CMR findings of RV wall motion abnormalities, reduced RVEF, and presence of LGE were consistent with the diagnosis of ARVC. However, two key points must be stressed in this context: the evidence of fat on CMR is not a recognized imaging criterion for the detection of ARVC; and the ARVC diagnosis cannot be based on imaging criteria alone [14,15].

Another important aspect of this case is represented by the presence of both right and left-sided abnormalities, consistent with the diagnosis of biventricular arrhythmogenic cardiomyopathy. Furthermore, the hypokinesia of the apical segment of lateral wall seen in this case agrees with the hypothesis to include the posterolateral LV within the 'triangle of dysplasia', as recently proposed [16]. It is also known that patients with more extensive RV or LV disease have a higher arrhythmic risk [17,18], so the author's decision to implant a subcutaneous defibrillator in this patient is more than reasonable. 
Despite the right ventricle can be difficult to accurately assess, as a result of its shape and volume dependency, a recent history of cardiac syncope is an important risk marker for several lifethreatening diagnosis, so we recommend a full investigation in any case of exertional syncope. The diagnosis of athlete's heart represents an important challenge due to the phenotypic overlap between the cardiac adaptive remodeling and early pathological changes seen in inherited or acquired cardiomyopathies; however, we encourage an integrated multi-imaging approach that could be helpful in all cases of differential diagnosis.

\section{References}

1. Maron BJ, Doerer JJ, Haas TS, et al. Sudden deaths in young competitive athletes: analysis of 1866 deaths in the United States, 1980-2006. Circulation 2009;119:1085-92.

2. Corrado D, Basso C, Rizzoli G, et al. Does sports activity enhance the risk of sudden death in adolescents and young adults? J Am CollCardiol. 2003;42:1959-63.

3. Corrado D, Basso C, Pavei A, et al. Trends in sudden cardiovascular death in young competitive athletes after implementation of a preparticipation screening program. JAMA 2006;296:1593-601.

4. Reed MJ. Approach to syncope in the emergency department. Emerg Med J 2018;36:108-16.

5. Costantino G, Sun BC, Barbic F, et al. Syncope clinical management in the emergency department: a consensus from the first international workshop on syncope risk stratification in the emergency department. Eur Heart J 2016;37:1493-8.

6. Sharma S. Athlete's heart-effect of age, sex, ethnicity and sporting discipline. Exp Physiol 2003;88:665-9.

7. Caselli S, Maron MS, Urbano-Moral JA, et al. Differentiating left ventricular hypertrophy in athletes from that in patients with hypertrophic cardiomyopathy. Am J Cardiol 2014;114:1383-9.

8. Weiner RL, Baggish AL. Exercise-induced cardiac remodeling. Prog Cardiovasc Dis 2012;54:380-6.

9. Brandimarte F, Battagliese A, Pirillo SP, et al. A case of arrhythmogenic right ventricular dysplasia with biventricular involvement. Monaldi Arch Chest Dis 2019 (in press).

10. Zaidi A, Sheikh N, Jongman JK, et al. Clinical differentiation between physiological remodeling and arrhythmogenic right ventricular cardiomyopathy in athletes with marked electrocardiographic repolarization anomalies. J Am Coll Cardiol 2015;65:2702-11.

11. Scharhag J, Thunenkotter T, Urhausen A, et al. Echocardiography of the right ventricle in athletes' heart and hearts of normal size compared to magnetic resonance imaging: which measurements should be applied in athletes? Int J Sports Med 2010;31:58-64.

12. Oxborough D, Sharma S, Shave R, et al. The right ventricle of the endurance athlete: the relationship between morphology and deformation. J Am Soc Echocardiogr 2012,25:263-271.

13. De Innocentiis C, Ricci F, Khanji MY, et al. Athlete's heart: Diagnostic challenges and future perspectives. Sports Med 2018;48:2463-77.

14. Saguner AM, Vecchiati A, Baldinger SH, et al. Different prognostic value of functional right ventricular parameters in arrhythmogenic right ventricular cardiomyopathy/dysplasia. Circ Cardiovasc Imaging 2014;7:230-9.

15. Brun F, Di Nora C, Merlo M, et al. Arrhythmogenic right ventricular cardiomyopathy: Clinical assessment and differential diagnosis. In: Pinamonti B, Sinagra G, editors. Clinical echocardiography and other imaging techniques in cardiomyopathies. Cham; Springer: 2014. pp. 37-45.

16. Te Riele ASJM, James CA, Philips B, et al. Mutation-positive arrhythmogenic right ventricular dysplasia/cardiomyopathy: the triangle of dysplasia displaced. J Cardiovasc Electrophysiol 2013;24:1311-20.

17. Patel DR, Luckstead EF Sr. Update on cardiovascular screening: can we prevent sudden cardiac death in adolescent athletes? Adolesc Med State Art Rev 2013;24:225-41.

18. Brun F, Di Nora C, Zecchin M, et al. Arrhythmogenic right ventricular cardiomyopathy: Usefulness of imaging in prognostic stratification and choice of treatment. In: Pinamonti B, Sinagra G, editors. Clinical echocardiography and other imaging techniques in cardiomyopathies. Cham; Springer: 2014. pp.173-181. 